\title{
Comparing trends in the use and outcomes of non invasive ventilation (NIV) in a general intensive care unit
}

\author{
L Wilson, J Gross', G Gallagher, A Wolff \\ From ESICM LIVES 2015 \\ Berlin, Germany. 3-7 October 2015
}

\begin{abstract}
Introduction
There has been an increase in the use of non-invasive ventilation (NIV) in the intensive care setting. Guidelines suggest more favourable outcomes when used in patients with chronic obstructive pulmonary disease (COPD) and cardiogenic pulmonary oedema $(\mathrm{CPO})\left[^{1}\right]$, yet its use often extends beyond these indications despite no evidence of clear benefit.
\end{abstract}

\section{Objectives}

To review the practice and outcomes of NIV in our institution over a 1 year period.

\section{Methods}

We conducted a retrospective analysis of all patients receiving NIV for the first time at any stage of their ICU admission between $1^{\text {st }}$ January 2014 and $31^{\text {st }}$ December 2014. Patients were divided into 3 groups: decompensated respiratory failure (DRF) $(\mathrm{pH}<7.35+\mathrm{pCO} 2>6 \mathrm{KPa}$ preNIV), non-decompensated respiratory failure (NDRF) $(\mathrm{pH}>7.35$ or $\mathrm{PCO} 2<6 \mathrm{Kpa}$ pre-NIV) or post extubation. For each patient, the indication and duration of NIV was recorded along with important outcomes that included requirement and duration of mechanical ventilation (MV), length of ICU stay and survival to ICU discharge.

\section{Results}

103 patients received NIV as a first line respiratory supportive therapy for a number of indications of which only $20 \%$ included COPD or CPO (figure 1).

38 had DRF and 63 NDRF prior to initiation of NIV. Despite those with DRF having significantly higher

Royal Free London NHS Foundation Trust, Intensive Care Unit, Barnet Hospital, London, United Kingdom

(c) 2015 Wilson et al.; This is an Open Access article distributed under the terms of the Creative Commons Attribution License (http:// creativecommons.org/licenses/by/4.0), which permits unrestricted use, distribution, and reproduction in any medium, provided the original work is properly cited. predicted acute hospital mortality than NDRF according to admission ICNARC scoring (49\% [IQR 28-62] vs. $36 \%$ [IQR 10-54] $\mathrm{p}=0.017$ ), median duration of NIV received was similar (23 [IQR 11-105] and 17 [IQR 8-73.5] hours for DRF and NDRF respectively $(\mathrm{p}=0.13)$ ). There were no significant differences between DRF and NDRF with respect to $\%$ of patients requiring subsequent mechanical ventilation $(29 \%$ v $43 \%$; $p=0.16)$, median duration of mechanical ventilation for those subsequently intubated (8 [IQR 4-11] vs. 9 [IQR 6-18] days; $\mathrm{p}=0.76$ ) or \% surviving to ICU discharge $(71 \%$ v $71 \%$; $p=0.97)$. There was a non-significant trend towards reduction in ICU length of stay (LOS) for those with DRF compared with NDRF (median ICU LOS 5.2 [IQR 3.1-8.9] v 9.8 [IQR 4.7-12.8] days respectively; $\mathrm{p}=0.052$ ).

NIV following a period of mechanical ventilation was given for 31 patients. In this cohort, NIV was administered for a median duration of 21 hours (range 1-617 hours). $13 / 31$ patients $(42 \%)$ required re-intubation and further periods of mechanical ventilation.

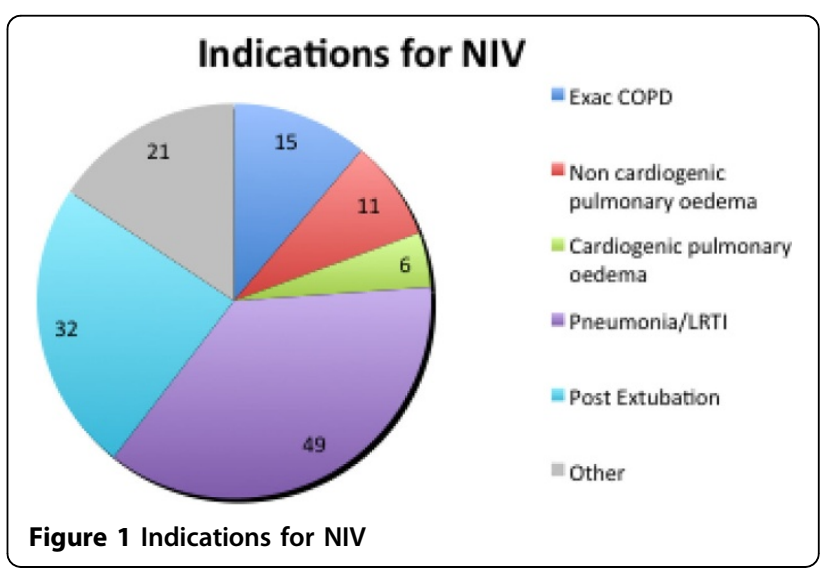




\section{Conclusion}

In our institution, the majority of patients received NIV for indications outside those recommended by guidelines. Those with DRF receiving NIV fared no worse compared with NDRF in this cohort. This along with those receiving NIV following extubation may provide a cohort of patients who warrant further investigation.

Published: 1 October 2015

\section{Reference}

1. Clinical practice guidelines for the use of noninvasive positive-pressure ventilation and noninvasive continuous positive airway pressure in the acute care setting. CMAJ 2011, E183-E241.

doi:10.1186/2197-425X-3-S1-A675

Cite this article as: Wilson et al.: Comparing trends in the use and

outcomes of non invasive ventilation (NIV) in a general intensive care

unit. Intensive Care Medicine Experimental 2015 3(Suppl 1):A675.

\section{Submit your manuscript to a SpringerOpen ${ }^{\mathcal{O}}$ journal and benefit from:}

- Convenient online submission

- Rigorous peer review

- Immediate publication on acceptance

- Open access: articles freely available online

- High visibility within the field

- Retaining the copyright to your article

Submit your next manuscript at $\gg$ springeropen.com 